Іванов О. М., кандидат технічних наук, Арендаренко В. М., кандидат технічних наук, Тиеджсо Уако Гі Патріс, матістрант

Полтавська державна аграрна академія

\title{
ВИЗНАЧЕННЯ ХОЛОДОПРОДУКТИВНОСТІ ТЕРМОЕЛЕКТРИЧНОГО МОДУЛЯ ПЕЛЬТ'С НА ОСНОВІ БАГАТОФАКТОРНОГО ЕКСПЕРИМЕНТУ
}

\section{Рецензент - кандидат технічних наук В. І. Левчук}

Наведена методика визначення холодопродуктивності термоелектричного модуля Пельт'є, який перетворює енергію електричного струму на теплові потоки з різним вектором направленості. Дослідження проводились із залученням методології планування та проведення багатофакторних експериментів. На основі експериментальних та аналітичних розрахунків було виведене апроксимоване рівняння другого роду, щзо дає змогу визначати значення холодопродуктивності термоелектричного модуля в иироких межах зміни двох визначальних факторів: величини сили струму та температури тепловипромінювальної сторони модуля.

Ключові слова: холодопродуктивність, ефект Пельт'є, термоелектричний модуль, визначальні фактори, експеримент, сила струму, рівняння апроксимаціï.

Постановка проблеми. Використання термоелектричного перетворювача на основі ефекту Пельт'є (модуль Пельт'є), як засобу штучного охолодження, відоме достатньо давно. Бурхливий розвиток даного методу отримання низьких температур почався із середини XX століття завдяки плодотворній роботі вчених під керівництвом академіка А. Ф. Іоффе по вивченню та застосуванню напівпровідникових елементів у різних галузях виробництва, зокрема в сфері конструювання електрогенераторних установок на основі напівпровідникових термоелементів [2].

У наш час застосування модуля Пельт'є, не зважаючи на його дорогу вартість та достатньо низьку термодинамічну ефективність, набуло широкого застосування. Даний модуль використовується не тільки в побутовій сфері (автомобільні та мобільні переносні холодильники та засоби мікроклімату), але й в таких високотехнологічних областях як: медицина, аерокосмос, радіоелектроніка, точне машинобудування, енергетика та інші [4].

Тому застосування модуля Пельт'є в науковопрактичному або побутово-прикладному плані вимагає вирішень питань, направлених на доведенні його економічної та технічної доцільності використання, на основі вивчення його електротехнічних та термодинамічних характеристик. Зокрема дослідження зміни холодопродуктивності модуля Пельт'є від визначальних факторів, що впливають на формування чисельної характеристики цього ключового параметра.

Аналіз останніх досліджень і публікацій, у яких започатковано розв'язання проблеми. Загальновідомо, що позитивний холодильний ефект - холодопродуктивність термоелектричного модуля прямим чином залежить від теплового балансу між трьома взаємовиключними енергетичними складовими: теплоти Пельт'є, що визначається кількістю теплової енергії, поглинутої іззовні холодною стороною термоелектричного модуля, джоулівського тепла та інтегральною величиною теплового потоку, що за рахунок явища теплопровідності передається від високо- до низькотемпературної сторони модуля Пельт'є. Перша 3 перелічених - формує позитивну частину балансу, а інші дві - в своїй сукупності $€$ нівелюючим чинником, що призводить до зменшення потенційної кількості теплоти, поглинутої на холодній стороні термоелектричного модуля [1].

3 вищевикладеного не важко встановити, від яких параметрів буде залежати холодопродуктивність модуля Пельт'є. Так, джоулівське тепло та теплота Пельт'є визначається, головним чином, одним функціональним параметром - силою струму, що протікає через термоелементи модуля. А кількість теплової енергії, що передається від гарячої до холодної сторони, обумовлюється різницею температури на теплопоглинаючій та тепловипромінюючій сторонах модуля. Тоді можна стверджувати про вплив на формування чисельної характеристики холодопродуктивності двох факторів: сили струму та температурній різниці на протилежних сторонах модуля Пельт'є. Водночас термодинамічні та електротехнічні параметри напівпровідникових термоелементів модуля Пельт'є не беруться до уваги по причині неможливості варіювати їхніми величи- 
нами під час експлуатації модуля.

$\mathrm{y}$ технічних документаціях термоелектричних модулів саме сила струму та різниця температури (температура гарячої сторони) приведенні як визначальні фактори, на підставі яких формуються чисельні вихідні характеристики зміни холодопродуктивності. Проте отримані залежності, в більшості випадках, були визначені виключно в «стерильних» лабораторних умовах, які дещо віддаленні від реальних умов експлуатації модуля [5].

За мету даного дослідження було поставлено пошук математичного відображення залежності холодопродуктивності термоелектричного модуля від визначальних факторів, що обумовлюють його технічний результат та визначають його термодинамічну ефективність.

Завданням є викладення чіткого послідовного алгоритму знаходження величини холодопродуктивності модуля в окремо взятій точці, координати якої задаються силою струму та температурою гарячої сторони модуля.

Результати дослідження. Як було сказано вище, холодопродуктивність термоелектричного модуля $\epsilon$ функцією від двох змінних параметрів: сили струму та температури гарячої сторони модуля. 3 чого випливає, що дослідження характеру зміни шуканої функції від визначальних параметрів слід знаходити, використовуючи методологію проведення багатофакторних експериментів, зокрема ту іiі частину, що передбачає планування експериментів, результат яких зале- жить від спільної дії двох факторів [3].

У загальному випадку холодопродуктивність, як функція, може описуватися у вигляді залежності:

$$
Q=f\left(I ; T_{2}\right),
$$

де $\mathrm{Q}$ - холодопродуктивність, Вт;

I - сила струму, A;

$\mathrm{T}_{\mathrm{r}}$ - температура гарячої сторони термоелектричного модуля, ${ }^{\circ} \mathrm{C}$.

У відповідності до методології двофакторного експерименту залежність (1) може бути представлена у вигляді багаточлену другого порядку [3]:

$Q=a_{0}+a_{1} \cdot I+a_{2} \cdot T_{2}+a_{11} \cdot I^{2}+a_{22} \cdot T_{2}^{2}+a_{12} \cdot I \cdot T_{2}$,

де $\mathrm{a}_{0}, \mathrm{a}_{1}, \mathrm{a}_{2}, \mathrm{a}_{11}, \mathrm{a}_{22}, \mathrm{a}_{12}$ - безрозмірні коефіцієнти апроксимації.

Для пошуку коефіцієнтів апроксимації був обраний план експерименту (рис. 1) 3 центральним розміщенням дослідних точок, що обумовлено усталеною практикою експлуатації термоелектричного модуля в області помірних значень сили струму та температури гарячої сторони. Водночас в якості екстремумів визначальних факторів приймалось: для сили струму $-\mathrm{I}_{\min }=0,7$ А та $\mathrm{I}_{\max }=9,3 \mathrm{~A}$; для температури гарячої сторони - $T_{2}^{\min }=30^{\circ} \mathrm{C}$ та $T_{2}^{\max }=50^{\circ} \mathrm{C}$. Крок нормування становив: для сили струму $-\Delta \mathrm{I}=2,2 \mathrm{~A}$, для температури гарячої сторони $-\Delta \mathrm{T}_{\mathrm{r}}=5{ }^{\circ} \mathrm{C}$.

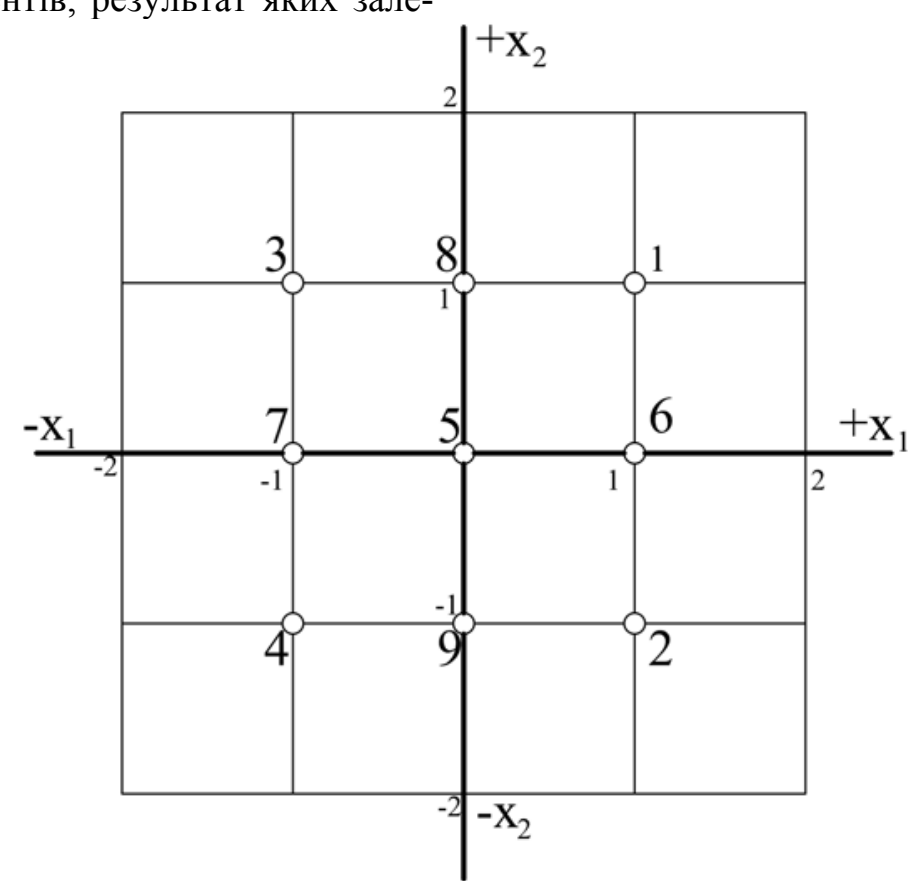

Рис. 1. Розтащування дослідних точок за центрального варіанта плану експерименту 


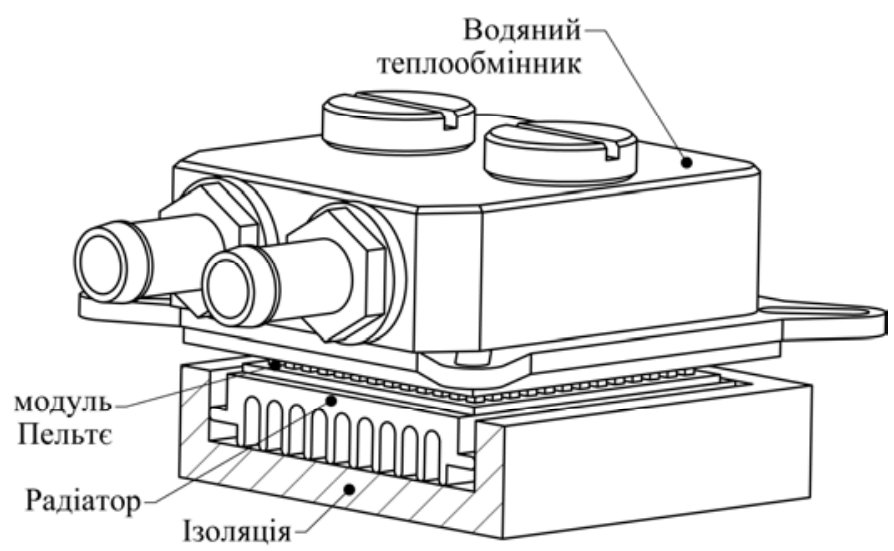

Рис. 2. Дослідна установка

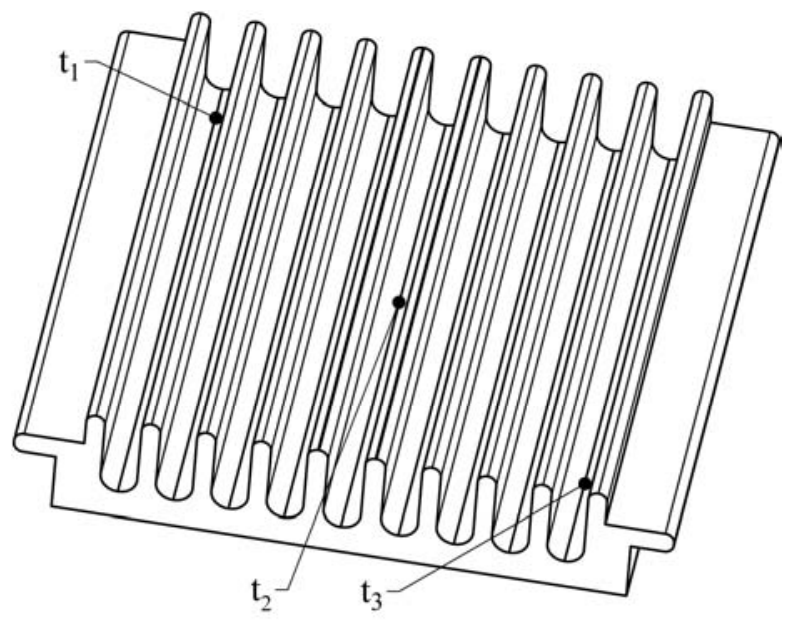

Рис. 3. Схема розташування датчиків температури на поверхні радіатора
Для проведення запланованих експериментів була створена лабораторна установка (рис. 2), ключовим елементом якої $\epsilon$ термоелектричний модуль Пельт' $\epsilon$ - ТЕС-12710.

На поверхні гарячої сторони модуля закріплений водяний теплообмінник, що відводить від цієї поверхні зайве тепло, а на холодній стороні розташований радіатор, який виконує функцію тіла охолодження. Для запобігання надходження теплової енергії конвективним шляхом до радіатора використовується теплоізоляція, яка огортає охолоджувальне тіло з усіх сторін.

Для здійснення моніторингу зміни температури радіатора використовувались цифрові сенсори температури, закріплені в декількох точках, по діагоналі, на поверхні радіатора (рис. 3).

Відстеження зміни температури гарячої сторони проводилося температурним датчиком, який встановлювався безпосередньо на гарячій стороні модуля (всередині тепловідвідного елементу водяного теплообмінника). Усі температурні показники фіксувались багатоканальним комутаційним мікроконтролерним термометром 3 точністю до $0,1^{\circ} \mathrm{C}$.

Для покращання контакту між теплообмінними площинами, які контактують між собою, та уникнення утворення повітряного теплоізоляційного прошарку між ними наносилась тонким шаром теплопровідна паста КПТ-8. Таке 3'єднання зчленованих теплообмінних елементів установки мінімізує вплив теплового опору цього шару на процес розповсюдження тепла між поверхнями. Живлення модуля Пельт'є здійснювалось від джерела постійного струму, який давав змогу забезпечувати сталість сили струму по всьому діапазоні зміни, визначеного умовами проведення запланованого двофакторного екс- перименту. Варіювання та сталість температури гарячої сторони модуля Пельт'є, у відповідності до плану експерименту, забезпечувалося шляхом зміни кількості охолоджувальної води, що надходила до водяного теплообмінника на відбір тепла від тепловідвідного елементу, спряженого з гарячою стороною модуля.

Процедура проведення експерименту для кожної дослідної точки плану полягала у відстеженні в часі зміни температури радіатора в трьох різних точках від початку подачі живлення із заданою силою струму на клеми термоелектричного модуля до моменту стабілізації температури радіатора у контрольних точках.

Холодопродуктивність визначалась як відношення кількості відведеної від радіатора теплової енергії до величини дискретного часового проміжку, що вибирався в якості сталого кроку хронометрування експерименту:

$$
Q=\frac{E_{\text {вid }}}{\tau},
$$

де $E_{\text {від }}$ - кількість відведеної теплової енергї̈ від радіатора, Дж;

$\tau-$ дискретний часовий проміжок, $\mathrm{c}, \tau=1 \mathrm{c}$.

Кількість відведеної теплової енергії від радіатора обраховувалась за виразом:

$$
E=m_{\text {pad }} \cdot c_{\text {pad }} \cdot \Delta t,
$$

де $m_{\text {pad }}$ - маса радіатора, кг, $m_{\text {pad }}=0,01935$ кг;

$c_{p a d}$ - теплоємність матеріалу, з якого виготовлено радіатора, Дж/(кг·К), $c_{p a d}=880$ Дж/кг·К; 
Результати двофакторного експерименту

\begin{tabular}{|c|c|c|c|c|c|}
\hline $\begin{array}{c}\text { Точка } \\
\text { плану }\end{array}$ & $\begin{array}{c}\text { Сила } \\
\text { струму } \\
,, \mathrm{A}\end{array}$ & $\begin{array}{c}\text { Температура } \\
T_{2},{ }^{\circ} \mathrm{C}\end{array}$ & $\begin{array}{c}\text { Дослідна холодопродук- } \\
\text { тивність } Q_{\partial}, \mathrm{BT}\end{array}$ & $\begin{array}{c}\text { Розрахункова холодо- } \\
\text { продуктивність } Q_{p}, \mathrm{BT}\end{array}$ & $\begin{array}{c}\text { Похибка } \\
\delta, \text { Вт }\end{array}$ \\
\hline 1 & 7,3 & 45 & 17,574 & 17,525 & 0,049 \\
\hline 2 & 2,9 & 45 & 8,616 & 8,370 & 0,246 \\
\hline 3 & 7,3 & 35 & 18,683 & 18,807 & $-0,124$ \\
\hline 4 & 2,9 & 35 & 11,761 & 11,688 & 0,074 \\
\hline 5 & 5,1 & 40 & 16,038 & 14,793 & 0,245 \\
\hline 6 & 5,1 & 45 & 14,417 & 17,012 & $-0,295$ \\
\hline 7 & 5,1 & 35 & 17,062 & 18,097 & 0,050 \\
\hline 8 & 7,3 & 40 & 18,171 & 9,960 & $-0,320$ \\
\hline 9 & 2,9 & 40 & 9,640 & 0 \\
\hline
\end{tabular}

$\Delta t$ - зміна температури радіатора під час охолодження в межах дискретного часового проміжку $\tau,{ }^{\circ} \mathrm{C}$.

Отримана вибірка холодопродуктивності кожної дослідної точки піддавалась аналізу на предмет пошуку максимального значення:

$$
Q_{\partial}=\max _{1 \leq i \leq n}\left\{Q_{i}\right\} .
$$

Знайдений екстремум вибірки ідентифікувався як дослідне значення холодопродуктивності термоелектричного модуля для відповідних зна-

$$
Q=19,9367+3,7184 \cdot I-0,6871 \cdot T_{2}-0,3647 \cdot I^{2}+0,0028 \cdot T_{2}^{2}+0,0463 \cdot I \cdot T_{2},
$$

Отримані експериментальні дані та результати аналітичних та статистичних розрахунків зведенні в таблиці.

3 таблиці бачимо, що відхилення величин дослідної та розрахункової холодопродуктивності $\epsilon$ достатньо невеликими, що свідчить про достатньо високу якість проведення експерименту та про добру збіжність результатів експерименту зі статистичною моделлю, вираженою отриманим рівнянням апроксимації.

Висновок. Запропонована методика визначення холодопродуктивності термоелектричного модуля

\section{БІБЛІОГРАФІЯ}

1. Холодильная техника. Энциклопедический справочник / [Бадилькес И. С., Бухтер Е. 3., Вейнберг Б. С. и др.]. - Л. : Госторгиздат, 1960. -543 с.

2. Иоффе Абрам Фёдорович [Электронный ресурс]. - Режим доступа : http://ru.wikipedia. org/wiki/ Иоффе_Абрам_Фёдорович.

3. Рафалес-Ламарка Э. Э. Некоторые методы планирования и математического анализа биологических экспериментов / Э. Э. Рафалес-Ламарка, чень сили струму та температури гарячої сторони модуля.

Отримана сукупність величин холодопродуктивності всього плану експерименту піддавалася регресійному аналізу, внаслідок чого було знайдемо коефіцієнти апроксимації $a_{0}, a_{1}, a_{2}, a_{11}, a_{22}$, $a_{12}$ криволінійної залежності (2).

Виведене рівняння апроксимації дає математичний опис характеристики зміни холодопродуктивності термоелектричного модуля:

3 використанням принципів планування та проведення багатофакторних експериментів дає змогу надати більш реальну оцінку термодинамічним властивостям термоелектричних модулів Пельт'є. Отримане рівняння апроксимації холодопродуктивності одного із таких модулів дасть можливість значно гнучко використовувати його можливості в реальних умовах експлуатації.

В. Г. Николаев. - К. : Наук. думка, 1971. - 119 с.

4. Что такое эффект Пельтье и термоэлектрический модуль? Элементы Пельтье [Электронный pecypc]. - Режим доступа : http://peltier. narod.ru/\#Что.

5. TEC1-12710. Datasheet [Електронний peсурс]. - Режим доступу : http://www.hebeiltd. com.cn/peltier.datasheet/TEC1-12710.pdf. 